\title{
Studies on the Origin of Milk Fat
}

\section{A FURTHER STUDY OF BOVINE SERUM LIPOPROTEINS AND AN ESTIMATION OF THEIR CONTRIBUTION TO MILK FAT}

\author{
By C. BISHOP, T. DAVIES, R. F. GLASCOCK AND V. A. WELCH \\ National Institute for Research in Dairying (University of Reading), Shinfield, Reading
}

(Received 5 February 1969)

\begin{abstract}
1. Tritium-labelled palmitic acid combined in olive-oil triglycerides was introduced into the rumen of a lactating cow and the specific radioactivity of the lipids of milk and of the lipoproteins of both jugular and mammary venous serum was measured. 2. As previously found in a similar experiment with $\left[{ }^{3} \mathrm{H}\right]$ stearic acid, the specific radioactivity of the triglyceride fraction of the dextran sulphate-precipitable lipoproteins reached a maximum earlier and greater than that of the milk fat. 3. This fraction was the only lipid separated that had a significant arteriovenous difference in concentration, and is therefore identified as the main circulating lipid precursor of milk fat. 4. Although the non-esterified fatty acids showed no arteriovenous difference in concentration, they showed a negative difference in specific radioactivity that could have occurred only at the expense of the triglycerides of the precipitable lipoproteins. 5. The mean specific radioactivity of the triglycerides immediately after removal from the blood is calculated and shown to be very close in value to that of the corresponding fraction in mammary venous serum. 6. By comparison of the mean specific radioactivities of milk fat and of this precursor, its contribution is calculated as $36 \%$. 7. This value is discussed with reference to the concentration of $\mathrm{C}_{16}$ and $\mathrm{C}_{18}$ fatty acids in milk fat and it is concluded that substantial amounts of these acids must have been derived from a source other than preformed circulating lipids.
\end{abstract}

In previous work (Glascock et al. 1966) $\left[{ }^{3} \mathrm{H}\right]$ stearic acid in the form of olive-oil triglycerides was administered to lactating cows and the specific radioactivity-time curves of lipids of serum lipoproteins and of milk were studied. They showed that only one circulating lipid, the triglyceride fraction of the precipitable lipoproteins, could have been solely responsible for all the radioactivity in the milk fat. [Precipitable lipoproteins are those precipitated from serum by dextran sulphate and previously called $\beta$-lipoproteins (Glascock et al. 1966).] It was calculated that the contribution of this fraction to milk fat was $35-48 \%$ according to whether the phospholipids made a large or negligible contribution.

The validity of this calculation depended on there being no differential utilization of the constituent fatty acids of this lipid fraction during incorporation into milk fat. Storry \& Rook (1964), however, have thrown doubt on the utilization for milk-fat synthesis of circulating palmitic acid taken up by the udder. The object of the present work was therefore to determine whether circulating palmitic acid is incorporated into milk fat, and to provide more information on the contribution of the triglycerides and phospholipids of the precipitable lipoproteins to milk-fat synthesis. A preliminary account of part of this work has been published (Welch, Bishop, Davies \& Glascock, 1968).

\section{EXPERIMENTAL}

Chemicals. Diethylene glycol succinate polyester and Chromosorb W (80-100 mesh) were supplied by Applied Science Laboratories Inc., State College, Pa., U.S.A. Merck silica gel $\mathbf{H F}_{254+366}$ was supplied by Camlab (Glass) Ltd., Cambridge. Light petroleum (b.p. $<40^{\circ}$ ) was supplied by May and Baker Ltd., Dagenham, Essex. Formic acid was A.R. grade. Anisole (general purpose reagent) was supplied by Hopkin and Williams Ltd., Chadwell Heath, Essex. Reference standard $\left[{ }^{3} \mathrm{H}\right]$ toluene was supplied by The Radiochemical Centre, Amersham, Bucks. Gifts of methyl palmitoleate from Dr J. Boldingh, Unilever Research Laboratorium, Vlaardingen, The Netherlands, and of reference mixtures of fatty acid methyl esters from the National Institutes of Health, Bethesda, Md., U.S.A., are gratefully acknowledged. Other chemicals were as specified by Glascock et al. (1966).

Tritium-labelled triglycerides. Methyl $\left[{ }^{3} \mathrm{H}\right]$ palmitate was prepared from methyl palmitoleate by the method of 
Glascock \& Reinius (1956). The radiochemical purity was shown by t.l.c. to be $99 \%$. The product was saponified and the free acid was introduced by transesterification ints oliveoil triglycerides (Bergström, Borgström \& Rottenberg, 1952), which were then purified by t.l.c. The triglycerides were diluted with $2 \cdot 5 \mathrm{~g}$. of olive oil and emulsified in $50 \mathrm{ml}$. of water as described by Glascock et al. (1966).

Experimental animal. A Friesian cow of the Institute herd, $546 \mathrm{~kg}$. in weight and yielding $10.4 \mathrm{~kg}$. of milk/day in her ninth month of lactation was kept without food for $20 \mathrm{hr}$. and the labelled emulsion, containing $93 \mathrm{mc}$ of ${ }^{3} \mathrm{H}$, was given by intra-ruminal injection. Blood samples (approx. 225 ml.) were taken at intervals from the jugular and mammary veins through polythene cannulas. Pitocin $(2 \mathrm{ml}$.) was injected through the cannula in the mammary vein and the animal was milked out completely just before being dosed and when milk samples were taken. She received $4 \mathrm{~kg}$. of hay and $4 \mathrm{~kg}$. of concentrates twice daily with free access to water.

Treatment of samples. All operations were carried out quantitatively in order that the weight or titre of the separated lipids could be used to calculate their concentrations with respect to the original sample of serum or milk.

The treatment of the milk samples, the precipitation of the serum lipoproteins and the extraction of lipids were carried out essentially as described by Glascock et al. (1966).

Thin-layer chromatography. The lipid extracts were submitted to t.l.c. on Merck silica gel $\mathrm{HF}_{254+366}$. The plate was developed three times in chloroform, which was allowed to rise to a distance of approx. $2 \mathrm{~cm}$. (Fessler \& Galley, 1964), then twice in diethyl ether-hexane-formic acid $(20: 80: 1$, by vol.). The plate was exposed to iodine vapour for 20 sec. and inspected under u.v. light of wavelength $366 \mathrm{~nm}$. The bands were marked, the iodine was removed in a current of nitrogen and the bands were transferred to Soxhlet thimbles $(50 \mathrm{~mm} . \times 10 \mathrm{~mm}$.) with a vacuum zone collector [Camlab (Glass) Ltd.]. The following lipid fractions (in order of decreasing mobility) were removed from the silica gel in the thimbles with the volumes of ether given in parentheses: cholesterol esters $(100 \mathrm{ml}$.); triglycerides (100 ml.); fraction C (100 ml.); NEFA* (200 ml.); diglycerides + cholesterol $(200 \mathrm{ml}$.); monoglycerides $(200 \mathrm{ml}$.). Fraction C, which formed a band very close to the triglycerides in two different solvent systems, has not yet been identified. Elution of the last band with ether removed the monoglycerides and left the phospholipids, which were then eluted with $200 \mathrm{ml}$. of $\mathrm{M}-\mathrm{HCl}$ in methanol (de Bohner, Soto \& de Cohan, 1965).

Gas-liquid chromatography. Milk lipids were treated as described by DeMan (1964) except that the solution of lipid in methanolic sodium methoxide was heated at $100^{\circ}$ instead of $60^{\circ}$. Selected samples of triglycerides were saponified and the fatty acids were methylated as described by Rogozinski (1964). The NEFA were treated similarly.

Chromatography was carried out in an Aerograph 1520 gas chromatograph. The analytical column was $150 \mathrm{~cm} . \times 3 \mathrm{~mm}$. and the preparative column was $150 \mathrm{~cm} . \times$ $6 \mathrm{~mm}$., constructed of stainless steel and charged with acidwashed Chromosorb W, loaded with $15 \%$ (w/w) diethylene glycol succinate polyester. The carrier gas was $\mathrm{N}_{2}$ at a flow rate of $25 \mathrm{ml} . / \mathrm{min}$. through the analytical column and $110 \mathrm{ml} . / \mathrm{min}$. through the preparative column. For all

* Abbreviation: NEFA, non-esterified fatty acids. analyses a temperature programme of $75-165^{\circ}$ was used with a rate of temperature increase of $8^{\circ} / \mathrm{min}$. The peaks on the chromatograms were identified and response factors evaluated by reference to chromatograms obtained from standard mixtures.

Selected fractions were collected on glass wool as described by Bennett \& Coon (1966).

Measurement of radioactivity. Radioactivity was measured at $12^{\circ}$ in a Packard Tri-Carb liquid scintillation spectrometer (model 3314). The scintillator solution used for counting the titrated fatty acids was methoxyethanol-anisole (3:2, $\nabla / v)$ containing 2,5-diphenyloxazole (7g./l.), 1,4-bis-(5phenyloxazol-2-yl)benzene $(0 \cdot 3 \mathrm{~g} . / \mathrm{l}$.) and naphthalene (100g./l.). The efficiency of counting was approx. $10 \%$. Methyl esters, separated by g.l.c., were counted with an efficiency of $40 \%$ in a toluene solution of 2,5-diphenyloxazole (4 g./l.) and 1,4-bis-(5-phenyloxazol-2-yl)benzene $(0 \cdot 3 \mathrm{~g}$. $/ \mathrm{l}$.). In all experiments the efficiency of counting was determined with $\left[{ }^{3} \mathrm{H}\right]$ toluene as internal standard.

Determination of concentration and specific radioactivity of lipids in serum and milk. (a) Milk fat and lipids of the nonprecipitable lipoproteins were determined gravimetrically in a counting vial. Scintillator solution was then added to the vial and the radioactivity determined.

(b) NEFA. The acids accompanying the non-precipitable lipoproteins, which include also the albumin-bound NEFA, were separated on a column of Florisil as described by Carroll (1961) except that formic acid-diethyl ether (1:24, $v / v$ ) was used to elute them. After removal of the solvent they were titrated in ethanolic solution under $\mathrm{N}_{2}$ with $4 \mathrm{~mm}-\mathrm{NaOH}$ with Nile Blue as indicator. Scintillator solution $(10 \mathrm{ml}$.) was then added to the vial and the radioactivity of its contents determined.

(c) Lipids of the precipitable lipoproteins. After elution from the chromatographic plates, all lipid fractions, except the phospholipids, were saponified and their fatty acids extracted and treated in the same way as the NEFA.

(d) Phospholipids. Phospholipid $\mathbf{P}$ was determined in a measured portion of each extract by the method of Bartlett (1959) after digestion with perchloric acid. The radioactivity was measured in another portion and the specific radioactivity of the fatty acids was then calculated by assuming a ratio of 2 moles of fatty acid/g.atom of $P$.

\section{RESULTS AND DISCUSSION}

Fig. 1 shows the specific radioactivity-time curves of the triglycerides of the precipitable lipoproteins of jugular serum, of milk fat and also, for comparison, of the total mixed lipids of the non-precipitable lipoproteins. These results agree with those previously obtained in experiments with $\left[{ }^{3} \mathrm{H}\right]$ stearic acid (Glascock et al. 1966) from which it was concluded that the triglycerides of the precipitable lipoproteins were the main, although not necessarily the only, circulating lipid precursor of milk fat.

G.l.c. showed that $94 \cdot 6 \%$ of the radioactivity in milk fat was in the $\mathrm{C}_{16}$ fatty acids, $4.6 \%$ was in higher and $0.8 \%$ was in lower fatty acids. It thus appears that the palmitic acid of the triglycerides of the precipitable lipoproteins is a precursor of the 
palmitic acid of milk fat and that there is very little chain-shortening or -lengthening of fatty acids during their passage from blood to milk.

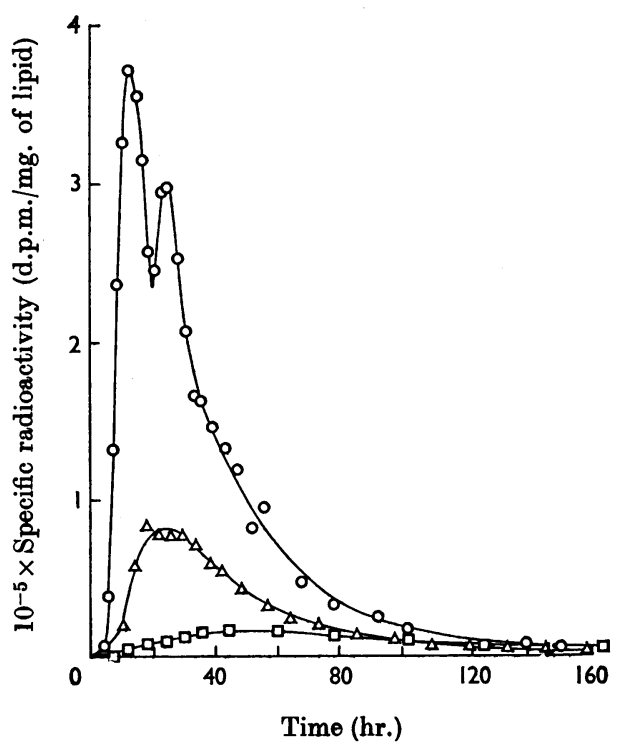

Fig. 1. Specific radioactivity of milk and blood lipids of a cow after administration of $\left[{ }^{3} \mathrm{H}\right]$ palmitic acid as olive-oil triglycerides. (O), Triglycerides of precipitable serum lipoproteins; $(\Delta)$, mixed lipids of milk; $(\square)$, mixed lipids of non-precipitable serum lipoproteins.
Table 1 shows the mean concentration and specific radioactivity of various lipid constituents of jugular and mammary venous serum. Calculations based on these results were made on the assumption that the concentration and specific radioactivity of the lipids in jugular serum are identical with those in arterial serum. Hartmann \& Lascelles (1965) have shown that the differences in concentration of most lipids as between carotid and jugular plasma are only about $5 \%$ and the above assumption does not therefore introduce any appreciable error into the calculations. To avoid unnecessary complication of the terminology, however, the term arteriovenous difference is used throughout the following discussion.

Table 1 shows that the only lipid with a significant arteriovenous difference in concentration was the triglyceride fraction of the precipitable serum lipoproteins, which is therefore identified as the only circulating lipid precursor of milk fat. In particular, the phospholipids whose participation was previously considered possible though not probable (Glascook et al. 1966) are eliminated as precursors by the present results. These results agree with those of Annison, Linzell, Fazakerley \& Nichols (1967), who found no arteriovenous difference in total plasma phospholipids, sterols, sterol esters or NEFA across the udder of the goat; and with those of Kronfeld (1965) and of West, Annison \& Linzell $(1967 a, b)$, who also found no arteriovenous difference in NEFA.

Table 1. Mean concentration and specific radioactivity of various lipid fractions of the lipoproteins of jugular and mammary venous serum

The values were calculated in most cases by integrating the graphs of concentration and specific radioactivity against time by using a planimeter and dividing by the time-interval over which the integration was performed. The values for the concentration of the total mixed lipids of the non-precipitable lipoproteins were obtained gravimetrically. The significance of the differences between the concentrations of the various fractions in jugular and mammary serum was assessed on the basis of the $t$ test for paired variants. N.S., $P>0.05$ (not significant); *** $P<0.001$.

\section{Lipid fraction}

Dextran sulphate-precipitable lipoproteins

Cholesterol esters

Triglycerides

Fraotion C

NEFA

Diglycerides

Monoglycerides

Phospholipids

Non-precipitable lipoproteins

Total mixed lipids

NEFA
Mean concn. ( $\mu$ moles of fatty acid/l. of serum)

$\overbrace{\text { Jugular } \begin{array}{c}\text { Mammary } \\ \text { venous }\end{array}}$
of differences in concn.

$\begin{array}{rr}39 \cdot 45 & 37 \cdot 22 \\ 75 \cdot 98 & 17 \cdot 44 \\ 4 \cdot 53 & 5 \cdot 91 \\ 22 \cdot 77 & 18 \cdot 37 \\ 21 \cdot 78 & 24 \cdot 67 \\ 24 \cdot 18 & 28 \cdot 11 \\ 93 \cdot 03 & 84 \cdot 01 \\ & \\ 2484 \dagger & 2485 \dagger \\ 128 \cdot 17 & 131 \cdot 17\end{array}$

$10^{-4} \times$ Mean specific radioactivity (d.p.m./ $\mu$ mole of fatty acid)

$\overbrace{\text { Jugular }}^{\begin{array}{c}\text { Mammary } \\ \text { venous }\end{array}}$


Table 1 also shows that the NEFA of the nonprecipitable lipoproteins leaving the udder had a higher specific radioactivity than those entering it. It is clear that this change could have occurred only at the expense of the triglycerides of the precipitable lipoproteins since the specific radioactivity of no other fraction was great enough.

A transfer of radioactivity from triglycerides to NEFA without any accompanying change in concentration of the NEFA implies that exchange has occurred. It has been shown (Welch et al. 1968) that at least two lipoproteins can be separated from the precipitable lipoproteins by ultracentrifugation, and the triglycerides attached to these lipoproteins could therefore have behaved as separate pools of which one or both might have exchanged with the NEFA before it was used for milk-fat synthesis.

The specific radioactivity of the material removed from the blood can be calculated for both these possible situations by considering 11 . of serum containing $\boldsymbol{R}_{\mathrm{AT}}$ and $\boldsymbol{R}_{\mathrm{AF}}$ d.p.m. of radioactivity in the form of triglycerides and NEFA respectively on entering the udder, and $R_{\mathrm{VT}}$ and $R_{\mathrm{VF}}$ d.p.m. on leaving it. (The $R$ terms are the product of specific radioactivity and concentration of the material in question.)

In the situation where the NEFA exchange only with that part of the triglyceride removed from the blood, that part has a total radioactivity of $R_{\mathrm{AT}}-R_{\mathrm{VT}}$. The amount of radioactivity gained by the NEFA by exchange with it is $R_{\mathrm{VF}}-R_{\mathrm{AF}}$. The net loss of radioactivity from the blood is thus $R_{\mathrm{AT}}-R_{\mathrm{VT}}-R_{\mathrm{VF}}+R_{\mathrm{AF}}$ associated with $W_{\mathrm{AT}}-W_{\mathrm{VT}}$ $\mu$ moles of triglyceride, where the $W$ terms are the concentrations of triglyceride in $\mu$ moles/l. in arterial and mammary venous serum.

The specific radioactivity of the material removed from the blood is thus given by:

$$
S_{p}=\frac{R_{\mathrm{AT}}-R_{\mathrm{VT}}-R_{\mathrm{VF}}+R_{\mathrm{AF}}}{W_{\mathrm{AT}}-W_{\mathrm{VT}}} \text { d.p.m. } / \mu \mathrm{mole}
$$

If, as in the other possible situation, the NEFA exchange with all the triglycerides during passage through the udder, the total radioactivity of the triglycerides/l. of serum is $R_{\mathrm{AT}}$ and the radioactivity removed from them by exchange with the NEFA is $R_{\mathrm{VF}}-R_{\mathrm{AF}}$ d.p.m. The specific radioactivity of the triglycerides is then given by:

$$
S_{p}=\frac{R_{\mathrm{AT}}-R_{\mathrm{VF}}+R_{\mathrm{AF}}}{W_{\mathrm{AT}}} \mathrm{d} . \mathrm{p} . \mathrm{m} . / \mu \mathrm{mole}
$$

Substitution of the mean values shown in Table 1 for the variables in these equations gives values of $\bar{S}_{p}=1.867 \times 10^{4}$ from eqn. (1) and of $\bar{S}_{p}=1.897 \times 10^{4}$ from eqn. (2).

Eqns. (1) and (2) are different except where the concentrations and specific radioactivities of the triglycerides in mammary venous serum ( $W_{\mathrm{VT}}$ and $R_{\mathrm{VT}}$ ) are zero and where the value of $S_{p}$ as calculated by eqn. (1) is equal to the specific radioactivity of the triglycerides in mammary venous serum; i.e. where $S_{p}=R_{\mathrm{VT}} / W_{\mathrm{VT}}$. Eqns. (1) and (2) then become identical.

As substitution in these equations of the observed values of the variables gives values of $\bar{S}_{p}$ that are nearly identical and also very close to the observed specific radioactivity of the mammary venous triglycerides $\left(1.996 \times 10^{4}\right.$ d.p.m./ $\left.\mu \mathrm{mole}\right)$, it would appear that the assumptions on which eqn. (2) are based is valid. Hence, insofar as exchange with the NEFA is concerned, the triglycerides of the precipitable serum lipoproteins appear to have formed a single pool whose specific radioactivity after exchange was the same as that of the remainder of this fraction which appeared in mammary venous serum.

West et al. (1967a) consider that in goats plasma NEFA are in equilibrium with the NEFA produced by the hydrolysis of plasma triglyceride, which in their view is almost certainly the first step in triglyceride uptake. If this were so in the present work, the mean specific radioactivity of the fatty acids after this equilibration would have been nearly $1 \frac{1}{2}$ times as great as that actually observed in the mammary venous NEFA. It therefore seems more likely that incomplete exchange between serum NEFA and triglycerides occurs at a stage before hydrolysis.

The probable sequence of reactions may be summarized as shown in Scheme 1. This scheme, of course, raises the question of the site of reactions (1) and (2), upon which the present work throws no light.

Fraction of milk fat derived from circulating lipid precursor. The mean molecular weight of the triglyceride fatty acids of the precipitable lipoproteins was found to be 270 by g.l.c. Their mean specific radioactivity, $\bar{S}_{p}$, of $1.897 \times 10^{4}$ d.p.m./ $/ \mu$ mole, as given by eqn. (2), corresponded to $6.702 \times 10^{4}$ d.p.m./mg. of triglyceride, whereas that of the milk, $\bar{S}_{m}$, was found to be $2.420 \times 10^{4}$ d.p.m./mg. The proportion, $x$, of milk fat, derived from this precursor is given by $\bar{S}_{m} / \bar{S}_{p}$ which thus has a value of $36 \%$.

This value cannot validly be compared with that of $48 \%$ obtained previously (Glascock et al. 1966) as in that experiment the data necessary for the calculation of the specific radioactivity of the triglycerides immediately after removal from the blood (eqns. 1 and 2) were not obtained. Nevertheless, it is of interest to examine the bearing of the value obtained on other parameters.

On the assumption that all the lipid removed from the blood during its passage through the udder was secreted into milk, a minimum value for the rate of flow of blood can be calculated from the mean 


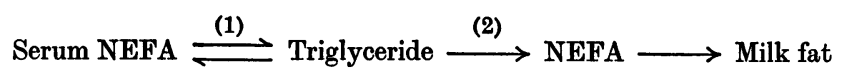

Scheme 1.

arteriovenous difference in the concentration of the triglycerides (58.6 $\mu \mathrm{moles} / 1$. of serum; Table 1), the mean molecular weight of their fatty acids (270), the haematocrit $(40 \%)$, the mean rate of secretion of milk fat (356.7mg./min.) and $x$. For $x=36 \%$, the rate of flow of blood is 131./min., which is within the normal range 7-171./min. suggested by Glascock \& Wright (1962) though somewhat higher than the mean value of $\mathbf{7 . 5 3 1}$./min. found by Kronfeld, Raggi \& Ramberg (1968).

Since 1951 it has been generally believed that in both cow and goat all the fatty acids of milk up to $\mathrm{C}_{16}$ are synthesized at least in part from small molecules, but that the $\mathrm{C}_{18}$ fatty acids are derived exclusively from blood lipids (for reviews see Glascock, 1958; Barry, 1964). Barry (1964) considers that up to $30 \%$ of the palmitic acid of goat's milk may be derived from synthesis and this conclusion is supported by the more recent work of Annison et al. (1967), who also conclude that all the $\mathrm{C}_{18}$ fatty acids originate in blood lipids.

In the present work, the milk fat of the cow contained $39 \% \mathrm{C}_{16}$ fatty acids and $32 \% \mathrm{C}_{18}$ fatty acids. If all these $\mathrm{C}_{18}$ fatty acids were derived from the triglyceride fraction of the precipitable lipoproteins, then a value for $x$ of $36 \%$ would leave little or no room for milk palmitate to be derived from that precursor. This would be inconsistent with the fact that the recovery of radioactivity in the milk fat was higher during the first $72 \mathrm{hr}$. of this experiment (35\% of the dose) than in the previous experiment with stearic acid ( $26 \%$ of the dose), which ended at $72 \mathrm{hr}$. (Glascock et al. 1966). It would also be inconsistent with the results obtained by other workers that point to an appreciable contribution of circulating palmitic acid to milk fat (Popják, French, Hunter \& Martin, 1951 ; Annison et al. 1967). Alternatively, if it is accepted that $70 \%$ of the $\mathrm{C}_{16}$ fatty acids and all the $\mathrm{C}_{18}$ fatty acids of milk fat are derived from the lipid precursor in the blood the value of $x$ would have to be at least $60 \%$. This in turn would require a rate of flow of blood of 221 . $/ \mathrm{min}$. which is almost certainly too high. It therefore seems that in the cow, at least, a larger proportion than $30 \%$ of the $\mathrm{C}_{16}$ fatty acids and possibly also an appreciable proportion of the $\mathrm{C}_{18}$ fatty acids are formed by synthesis. This conclusion is supported by the work of Gerson, Shorland, Wilson \& Reid (1968), who concluded that in the bovine udder there is appreciable synthesis of $\mathrm{C}_{18}$ fatty acids from acetate. A more precise evaluation of the contribution of individual fatty acids combined in the triglycerides of the precipitable serum lipoproteins to those in milk fat will necessitate their separation and a comparison of their specific radioactivities.

We thank Dr A. T. Cowie for insertion of cannulas and other minor surgery, Dr A. M. H. Al-Dawody for g.l.c., $\mathrm{Mr}$ S. H. Phillips for radioactivity measurements, $\mathrm{Mr}$ B. B. Brown and $\mathrm{Mr} \mathrm{V}$. W. Johnson for care and management of the cow and Mr D. R. Westgarth and Mr S. C. Puri for advice on statistical treatment of results. We also thank Mr M. G. Gee, Miss J. M. Sutton, Mr M. J. Cooney, Mr E. C. Needs, Mr D. B. Mason and Mr A. G. Low for technical assistance. This work received support through a grant to the Institute from the Agricultural Research Council, which is gratefully acknowledged.

\section{REFERENCES}

Annison, E. F., Linzell, J. L., Fazakerley, S. \& Nichols, B. W. (1967). Biochem. J. 102, 637.

Barry, J. M. (1964). Biol. Rev. 39, 194.

Bartlett, G. R. (1959). J. biol. Chem. 234, 466.

Bennett, M. \& Coon, E. (1966). J. Lipid Res. 7, 448.

Bergström, S., Borgström, B. \& Rottenberg, M. (1952). Acta physiol. scand. 25, 120.

Carroll, K. K. (1961). J. Lipid Res. $2,135$.

de Bohner, L. S., Soto, E. F. \& de Cohan, T. (1965). $J$. Chromat. 17, 513.

DeMan, J. M. (1964). J. Dairy Sci. 47, 546.

Fessler, J. H. \& Galley, H. (1964). Nature, Lond., 201, 1056.

Gerson, T., Shorland, F. B., Wilson, G. F. \& Reid, C. W. S. (1968). J. Dairy Sci. 51, 356.

Glascock, R. F. (1958). Proc. Roy. Soc. B, 149, 402.

Glascock, R. F. \& Reinius, L. R. (1956). Biochem. J. 62, 529.

Glascock, R. F., Welch, V. A., Bishop, C., Davies, T., Wright, E. W. \& Noble, R. C. (1966). Biochem.J. 98, 149.

Glascock, R. F. \& Wright, E. W. (1962). In The Use of Radioisotopes in Animal Biology and the Medical Sciences, vol. 2, p. 185. Ed. by Fried, M. London and New York: Academic Press Inc.

Hartmann, P. E. \& Lascelles, A. K. (1965). Aust. J. biol. Sci. 18, 114.

Kronfeld, D. S. (1965). Vet. Rec. 77, 30.

Kronfeld, D. S., Raggi, F. \& Ramberg, C. F., jun. (1968). Amer. J. Physiol. 215, 218.

Popják, G., French, T. H., Hunter, G. D. \& Martin, A. J. P. (1951). Biochem.J. 48, 612.

Rogozinski, M. (1964). J. Gas Chromat. $2,136$.

Storry, J. E. \& Rook, J. A. F. (1964). Biochem. J. 91, 27 c.

Welch, V. A., Bishop, C., Davies, T. \& Glascock, R. F. (1968). Biochem. J. 106, 17 P.

West, C. E., Annison, E. F. \& Linzell, J. L. (1967a). Biochem. $J .102,23$ P.

West, C. E., Annison, E. F. \& Linzell, J. L. (1967b). Biochem. $J .104,59$ P. 